\title{
Sorry as a Marker for Self-negation Used by Learners in Language Classrooms
}

\author{
Robin Ruowei Yang \\ School of Education and Languages, Open University of Hong Kong, China
}

Copyright $\bigcirc 2017$ by authors, all rights reserved. Authors agree that this article remains permanently open access under the terms of the Creative Commons Attribution License 4.0 International License

\begin{abstract}
This study analyzes the naturally occurring English word sorry in adult learners' talk in a language classroom and examines its role as a marker for self-negation from the perspective of pragmatic negation. The database for this study consists of 40 hours of video recordings of online tutorials for learning Chinese as a second language at a university in Hong Kong. The detailed analysis shows that to address various types of problematic utterances they make, learners do not always use an explicit negation operator such as no to negate their prior utterances but instead use sorry as an alternative. Rather than being used as a negation of a truth-functional operator for propositions, sorry is prominently used by learners as a device for objecting to a prior utterance in conversational implicature or other aspects of language use related to pragmatic negation. The findings also show that sorry plays a dual role by negating the prior utterance and predicting the next utterance, which may be either by the speaker or by the hearer, for correction. The reason for sorry being used as a marker for negation is discussed, and the study suggests that as sorry is perceived and understood maturely by speakers and hearers in context, it realizes the function of pragmatic negation.
\end{abstract}

Keywords Sorry, Pragmatic Negation, Alternative Form, Self-negation, Discourse Analysis

\section{Introduction}

Previous studies have examined linguistic negation by analysis of natural language. There are two distinct uses of natural language negation - internal and external or marked. Horn [1], who developed the concept based on Ducrot's [2, 3] concept of metalinguistic negation, argues that external or marked use must be treated not as a truth-functional or semantic operator for propositions but rather as a device for objecting to a previous utterance on any grounds, such as the conversational implicature, its morphology, style, register, and phonetic realization. In this sense, other scholars (Kruszewski, Paperno, Bernardi and Baroni [4]) also refer to external or marked negation as pragmatic or conversational negation, which, as a more inclusive term, also encompasses negation merely realized by context instead of negation operators (e.g., Jiang [5]). As such, this study prefers adopting pragmatic negation to metalinguistic negation for discussing relevant phenomena in the context of this study.

Whereas great attention has been paid to the study of internal negation, to date, external or marked negation has rarely been investigated, particularly in specific contexts. To fill in this research gap, this study explores the alternative plausibility of sorry acting as an external marker in the context of classrooms for language learning to understand how sorry acts as a device of pragmatic or conversational negation for language learners to make self-negations of their utterances.

According to English dictionaries, sorry, as an adjective has two lexical meanings that maybe relate to this study. The first is as an apology, used to indicate that one wishes one had not done something, especially with the intent of being polite to someone to whom you have done something negative. The second is saying no, used to show politeness when refusing something or disagreeing. However, when we observe learners' talk in the classroom, the use of sorry seems to not exactly reflect the above two meanings. Excerpt 1 below provides an example:

\section{Excerpt 1}

(Original utterances in Chinese are followed by English translation in italics, whereas statements that were originally in English are quoted verbatim.)

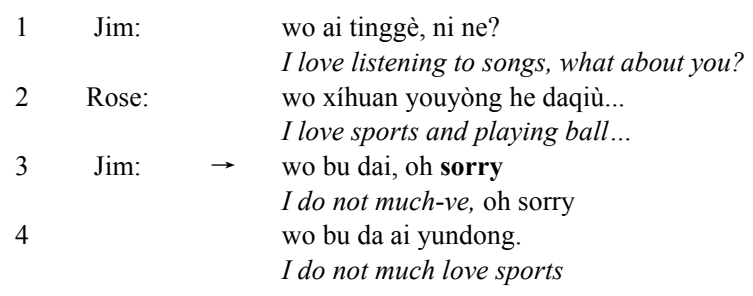

In this excerpt, two learners in the class are practicing by reading aloud the dialogue text by role play. In Jim's 
second turn, when he reads the Chinese sentence "wo bu da ai yundong', which means 'I do not much love sports', he incorrectly pronounces two syllables in Chinese, 'da' and 'ai', by combining them as 'dai' (line 3 ). Jim immediately realizes the mispronounced words, and following his 'oh, sorry', he makes a correction to the Chinese sentence (line 4).

Sorry used by Jim in this excerpt is neither an apology for offending others nor a refusal or disagreement with others. What does sorry mean in this context, and why does it have a meaning other than apologizing to or disagreeing with others?

This study analyzes the function and meaning of sorry used by language learners in a classroom from a pragmatic perspective. It focuses on sorry as a marker of self-negative evaluation and negation for an utterance, which serves pragmatic purposes. Using conversation analysis (CA), the study classifies the resources by which sorry plays a role in the expression of negative evaluation or negation into pragmatics and phenomena belonging to discourse semantics. Although the implications can go beyond functions of negation that sorry realized in the language learner's talk, discussing the relationship of sorry used in a first language (L1) and a second language (L2), or the relationship between the use of sorry and acquisition of L2, Chinese in this study, is not the goal of this study. Instead, this study attempts to contribute to the application of pragmatics and semantics for discourse analysis, although it is based on data captured in the context of L2 Chinese classroom.

As the study focuses on the English word sorry used by learners in the language classroom, whereas the language being learned is not a matter of concern regarding the use of sorry, we use the term 'speaker-learner' rather than 'L2 learner', to emphasize the position of the learner as a speaker, for analyzing and discussing related utterances in the following sections.

\section{Related Literature}

\subsection{Pragmatic Negation}

The literature on negation or negative evaluation in language use has recently demonstrated various aspects, such as its asymmetrical nature (Rozin and Royzman [6]; Garcia, Garas and Schweitzer [7]), taxonomy of resources (Taboada, Trnavac and Goddard [8]); lexicogrammar (Biber and Barbieri [9]), types of sentence structure (Sousa [10]), context effects (Orenes, Moxey, Scheepers and Santamaría [11]), logical connection (Horn and Wansing [12]), and others. Most of these studies have focused on truth-functional, presupposition-preserving ordinary negation, which can be classified as 'internal' negation involving something that is false or lacks truth-value. In contrast, 'marked' or 'external' negation, which has defined by Horn [1] as a device for registering objection to a previous utterance (not proposition) on any grounds, including the manner in which it was pronounced, has been studied only in terms of very limited aspects. Some studies (Jiang [5], p. 600) have argued that pragmatic negation is irrelevant to the truth condition of a proposition and consider it as a type of language skill adopted by speakers. However, many questions regarding actual use, format and function of pragmatic negation remain unanswered, and they require detailed and in-depth investigation. Furthermore, most studies of negation have focused on negative utterances, in which, as Foolen [13] (p. 220) indicates, 'the positive counterpart of that sentence has been uttered, usually by a different speaker immediately before the present negative utterance'. However, no study had noted the phenomenon of pragmatic negation operated by one speaker. In other words, no research has analyzed the nature of language for self-negating a previous utterance.

Foolen [13] (p.219) demonstrates Horn's discussion of metalinguistic negation for a formally negative utterance that is used to object to a previous utterance on any grounds, including the way it was pronounced, in the following example:

1) A: He called the pólice.

2) B: He didn't call the [pólis]; he called the [polís].

The negative conjunct of the example utterance (2B) rejects the (incorrect) pronunciation of the word 'police' as it occurs in A's utterance. Negation here primarily deals with issues of discourse and can be paraphrased as 'you should not pronounce that word in that way'. Indeed, the negation in the pragmatic utterance has nothing to do with any real-world state of affairs or, depending on the theory, with anything in the cognitive domain. Thus, Foolen [13] proposes the concept of two types of oriented negation: world-oriented and discourse-oriented, which in line with Horn's 'internal' and 'external' or 'marked'. However, these two types of negation have not received balanced attention. Whereas world-oriented negation has received considerable attention from researchers, few studies have addressed discourse-oriented negation.

Another aspect that has been almost completely ignored by studies is the phenomenon in which a speaker can propose negation by him/herself. Although studies have focused on the forms, signs, lexical meanings and functions of negation for the truth of a clause or sentence that states another proposition and has been proposed by other speakers, few studies have examined the self-negation by the speaker of his/her own prior utterance. Experience tells us that people do not only deny other's assertions or discourse but also sometimes deny or cancel an utterance produced by themselves.

To fill the gaps in the literature, again, this study attempts to analyze the use of sorry in classroom discourse and to discover its functions as a marker or an alternative form of negation, particularly for self-negation. 


\subsection{Studies of Sorry and Related Frameworks}

Many studies have found that sorry can have various functions, such as non-apology actions (Drew [14]; Robinson [15], [16]; Rhys [17]). In terms of its relationship with a source of difficulty, Rhys [17] noted that sorry as a self-repair initiation identifies a trouble source, i.e., a problem connected to an instance at an earlier turn, but does not repair it. Robinson's [15] study examined the sequential organization of sorry-based units and their different implications for conversational organization. Robinson found that in apology units, while initiating a sequence of action to provide an apology as the primary action, non-apology, such as condolences and other-initiated repair, occurred sometimes.

Some studies have found that sorry, always with upward intonation, can be used for other-initiated repair. Sorry, in special circumstances, can function to close down collaborative word searching and to move the conversation forward as a speaker displays his/her non-competence arising from, for example, aphasia, in difficulties with lexical choice [17]. Therefore, although sorry indexes with regret due to its linguistic capacity, its apology function is subordinate to its word-search closing function.

Sorry has been analyzed as an action related to conversational repair, as stated above. Because repair deals with something incorrect or repairable in a prior utterance, it contains a negative evaluation and furthers a negation of what has just been uttered. Thus, sorry should be analyzed from a perspective of pragmatic negation. Unfortunately, no previous studies have addressed this issue.

Alba-Juez and Martinez-Caro [18] analyzed the evaluative function as part of the hidden pragmatic meaning of certain expressions in English and Spanish and argued that a given word or expression can take on a negative association. Even when, from a strictly semantic perspective, these words do not have an inherently negative meaning, they are mostly associated with this type of meaning and occur most frequently in the context of other words or phrases that are predominantly negative in their evaluative orientation. Whereas both pragmatic and semantic studies are concerned with meaning, there is consensus in linguistics that semantic meaning involves the truth conditions of sentences and pragmatic meaning involves the use of utterances in a given context. Potts [19] argued that a negative expressivity derives not from the lexical meaning of negation alone but from pragmatic considerations and hearer expectations. Channel [20] explained that the encoding of attitude or evaluation can be either semantic or pragmatic. When it is semantic, the evaluative meaning is expressed overtly, whereas when it is pragmatic, the evaluative attitude is presented covertly. Therefore, the encoding of the real meanings of a word must examine its use in a specific context and from both sematic and pragmatic perspectives.

Given this context, the purpose of this study is two-fold. One is to determine how sorry is used as an alternative to the negation operator no or not for a prior utterance made by a speaker who is an adult learner of another language. The other purpose is to investigate how sorry is used as a pragmatic skill to negate an inappropriate utterance. In other words, the negation in this context is irrelevant to the truth condition of a proposition made by the speaker other than the one who negates it; rather, it functions as an external marker adopted by the speaker to negate his/her prior utterance in a classroom for language learning.

This study attempts to answer two specific questions: what are the meanings and functions of sorry in the same turn of utterance produced by a speaker-learner in classroom talk? What discourse and pragmatic features does sorry carry in this context?

\section{Data and Participants}

The data for this study were collected from a university in Hong Kong that provides a Basic Chinese for Non-Chinese Speakers (CSL) course via an online learning environment (OLE). In addition to providing all the multimedia material online, the course offers online tutorials (e-tutorials) to support learners' synchronous interactional learning. The setting is similar to a small classroom, albeit via video through the OLE.

This study uses existing data of videos recorded automatically by the OLE in the real setting of e-tutorials. The database consists of video recordings of 36 tutorial sessions with a total time of approximately 40 hours involving three tutors (one female and two male) and 13 adult learners (six female and seven male). Two to five learners participated in each session. All video recordings were transcribed following $\mathrm{CA}$ transcription conventions (Hutchby and Wooffitt [21]; Jefferson [22]) and with reference to the pilot transcription for this study.

In the e-tutorials, English is used as the medium of instruction. A learner can see the tutor and other learners in the group on screen if the other learners' cameras are on, and participants can converse synchronously with others through the system.

The CSL course is open to non-Chinese speakers from anywhere in the world, but most of the learners were working or living in Hong Kong at the time of this study. The learners in this study were adults aged 21 to 50, and English was the first language for those who were from the UK, Canada or the USA. Although four among 13 learners had mother tongues other than English, i.e., Spanish, German, Japanese and Hindi, all had high proficiency in English. All the learners had no or very little experience in learning Chinese before enrolling in the course.

All the learners who enrolled in this course were aware that the e-tutorials they attended would be video recorded and archived in the OLE system. Learners who were absent from any session of the e-tutorials or who wanted to self-review the e-tutorials could revisit the recorded 
e-tutorials anytime during the course presentation by logging into the system. The learners' consent to the use of relevant recordings as data for this study was obtained prior to the analysis.

\section{Detailed Analysis}

In Excerpt 1 (discussed previously), after mispronouncing words, Jim says sorry and then immediately re-utters the words with the correct pronunciation. The purpose of sorry used by Jim is to negate his own prior utterance. It is a pragmatic negation of the speaker self, Jim in this case.

The data for this study indicate that to address various types of difficult utterances that they make, speaker-learners do not often use explicit negation operators, such as no or not, to negate their previous utterances; instead, they use sorry followed, in most cases, by self-correction. Among 83 cases of the same turn in which sorry was used by a speaker who was having difficulty, $40(48.2 \%)$ of them suggest that sorry was used as a marker to immediately self-negate a prior utterance in ongoing talk and assist the learners in reaching their language learning and classroom interactional goals.

Detailed analysis of the data illustrates how sorry occurs in different contexts as a marker for negatively evaluating or negating a prior utterance that is accomplished by the speaker him/herself. The exemplified analysis follows.

\subsection{Assertion of one's Own Fault}

In the process of classroom interaction, a learner sometimes can recognize errors produced by her/his prior utterance with or without other (tutor)'s alert and uses sorry to indicate that $\mathrm{s} / \mathrm{he}$ would reproduce an utterance and negate the prior one. Excerpt 2 below is an example of saying sorry before an assertion for one's own fault, which followed a self-correction.

\section{Excerpt 2:}

$(\mathrm{T}=$ tutor; Cathy or other names hereafter $=$ anonymous name for learner $)$

$\begin{array}{ccl}1 & \text { T: } & \text { mmm because here we...er ok? use... } \\ 2 & \text { Cathy: } \rightarrow & \text { it's all right, sorry, my fault } \\ 3 & & \text { it was...tang tang } \\ & & \text { it was...soup soup } \\ 4 & \text { T: } & \text { oh...ok. tang, doufu tang } \\ & & \text { oh...ok. soup, doufu soup }\end{array}$

In Excerpt 2, the tutor is asking Cathy to use the Chinese word 'tang' (soup) because Cathy did not do well in her previous turn before tutor's turn (line 1). Cathy does not wait for the tutor's turn to complete. She responds with 'it's all right', which shows her understanding of the tutor's request, and follows with 'sorry, my fault', which shows that she wishes to cancel her prior utterance because it was an error for which she is responsible. The presence of sorry followed by 'my fault' can be interpreted as 'because I made a mistake, I have to cancel it'. Then, Cathy attempts to correct her mistake (line 3 ).

\subsection{Self-negating a Prior Proposition}

In a tutorial session, the tutor led the learners in a lexical exercise with multiple choices that indicated Chinese words in Pinyin with different tones. The learner, Danny, negates prior choices twice and changes to the last one, which is correct.
Excerpt 3:

\begin{tabular}{|c|c|c|c|}
\hline 1 & Danny: & & ah, di san ge? \\
\hline & & & ah, the third one? \\
\hline 2 & $\mathrm{~T}:$ & & ah, xuěshēng? \\
\hline & & & ah, student ((wrong tones)) \\
\hline 3 & Danny: & $\rightarrow$ & ah, sorry, xuéshēng, di er \\
\hline 4 & & $\rightarrow$ & $\begin{array}{l}\text { ah, sorry, student ((wrong tones)), the second } \\
\text { ah, sorry, sorry, di yi! xué sheng. }\end{array}$ \\
\hline 5 & $\mathrm{~T}:$ & & $\begin{array}{l}\text { ah, sorry, sorry, the first! student. } \\
\text { di yi ge? right, it must be the first. }\end{array}$ \\
\hline & & & the first one? right, it must be the first. \\
\hline
\end{tabular}

Four Pinyin words are shown for the Chinese word 'student'. Danny chooses the third answer first (line 1). After the tutor reads the Pinyin word in the third answer, which presents its pronunciation with incorrect tones for the word (line 2), Danny recognizes that his selection is wrong. Danny pronounces the Chinese word after saying sorry and selects the second choice as the answer (lines 3). However, he immediately finds that the correct answer should be the first one, and he says sorry twice and eventually obtains the right answer (line 4), which is confirmed by the tutor (line 5).

What is negated by sorry in Danny's utterances are the propositions that Danny refers to in the third (line 1) and second (line 4) choices. In this excerpt, we can see that after sorry is used, Danny changes his mind about the prior selections twice and finally gives a correct answer. Sorry is used here three times by Danny to indicate that he is negating/denying his own assertions (about word selection). Danny does not use the linguistic marker no or not to deny two of the incorrect selections he has made; he only uses sorry, which successfully negates his prior assertions. If sorry were absent in the utterances, logically, Danny must use no or not to negate the assertions. In this sense, the function of negation that sorry has is prominent.

In Excerpt 3, sorry is used by a learner to self-negate the assertions proposed by the speaker himself, which are attributed to a type of world-oriented negation.

\subsection{Self-negating Utterance on Incorrect Track}

When mistakes in conversational organization occur, although they are not actual errors in language performance, 
a speaker-learner uses sorry to cancel his/her prior utterance and make redirections to line up with the conversational sequence. An example below in Andrew's utterance can illustrate this type of pragmatic function.

\section{Excerpt 4}

\begin{tabular}{|c|c|c|}
\hline $\mathrm{T}$ : & & you mei you youhui? \\
\hline Andrew: & & $\begin{array}{l}\text { you mei you youhui? } \\
\text { is there any discount? }\end{array}$ \\
\hline & $\rightarrow$ & er, sorry \\
\hline & & $\begin{array}{l}\text { zhe jia shangdian shi bu jiangjia de } \\
\text { this shop cannot bargain price }\end{array}$ \\
\hline
\end{tabular}

In this excerpt, Andrew is performing a role-play with the tutor to practice specific Chinese expressions for shopping. After the tutor inquires about a discount (line 1), Andrew should respond with the designated pattern of a Chinese sentence. However, Andrew does not respond to the tutor's question and repeats the question first (line 2). His 'er' shows that he is aware of the mistake he made, and he uses sorry to indicate a cancellation of his prior utterance (line 3 ) and the correct utterance that he produces successfully (line 4). Sorry here (line 3) can be interpreted as 'what I said is not correct; I should say the following sentence', which is a device for changing or alternating talk from the current point to another that Andrew should utter. Sorry here is not meant to evaluate the truth-value of the utterance but rather to negate the prior utterance, which is an incorrect reaction in this interaction. It is a conversation-oriented self-negation and self-correction for a prior utterance.

\section{Excerpt 5}

\begin{tabular}{|c|c|c|c|}
\hline 1 & Fiona: & & yeah, I've got to say Zhōng xiăojie \\
\hline & & & yeah, I've got to say miss Zhong \\
\hline 2 & & & $\begin{array}{l}\text { or pretend you were me. ok. } \\
\text { or pretend you were me. ok. }\end{array}$ \\
\hline 3 & $\mathrm{~T}:$ & & $\begin{array}{l}\text { zăoshang hăo, Zhōng....ah Zhōng xiăojie...@ } \\
\text { good morning, Zhong... ah miss Zhong...@ }\end{array}$ \\
\hline 4 & Fiona: & $\rightarrow$ & $\begin{array}{l}\text { Zhōng xiăo...Oh, ah, sorry, } \\
\text { Zhong mi... oh, ah, sorry, }\end{array}$ \\
\hline 5 & & & I'm confused... \\
\hline
\end{tabular}

Excerpt 5 shows that in the class activity, Fiona says that she understands that she should present the other person in a dialogue with the tutor (line 1). However, after the tutor greets her by calling her Miss Zhong (line 3), she repeats 'Miss Zhong' and then finds that she should respond as the other person to the greeting. Thus, she uses sorry to negate her utterance. However, unlike the case of Excerpt 3, after saying sorry, she does not make an immediate correction (i.e., change the track of talk). Instead, she says 'I'm confused...,' which is an explanation for the reason for her mistake (line 5).

\subsection{Negatively Evaluating an Utterance in the Target Language}

Because the context of this study is classroom interaction for learning another language, the speaker-learner often utters with errors in pronunciation, lexis and grammar for the target language. In this situation, the speaker uses sorry to negate or cancel what s/he just uttered, and typically would like to produce a new utterance to make corrections by her/himself.

\begin{tabular}{|c|c|c|c|}
\hline \multicolumn{4}{|c|}{ Excerpt 6} \\
\hline 1 & $\mathrm{~T}:$ & & $\begin{array}{l}\mathrm{mm} \text {. women za...gaitian zai kan dianying } \\
\mathrm{mm} \text {. we ag...other day again watch movie }\end{array}$ \\
\hline 2 & Sue: & $\rightarrow$ & $\begin{array}{l}\text { women gái...ahem sorry } \\
\text { we other... ahem sorry }\end{array}$ \\
\hline 3 & & & $\begin{array}{l}\text { women gàitian zai kan dianying } \\
\text { we other day again watch movie }\end{array}$ \\
\hline
\end{tabular}

In Excerpt 6, Sue follows the tutor (line 1) to read a Chinese sentence, which contains a few new words that she needs to learn. When Sue reads 'gai' in the Chinese word 'gaitian' with the wrong tone as 'gái' (line 2), she discontinues her reading because she is aware of the problem. After a short pause and 'ahem' (showing her hesitation), she uses sorry to indicate that she denies the 'gái' she just pronounced and then re-pronounces it again immediately. Though Sue reproduces another incorrect sound for the Chinese word 'gaitian', she uses sorry to show that she negatively evaluating the utterance she initially produced and follow it with a correct one, even though she actually produces another incorrect utterance (line 3).

This interpretation of sorry followed an intended correction finds support in Excerpt 7, which is in a similar context to the use of sorry in Excerpt 6.

\section{Excerpt 7 \\ $1 \quad$ Sue: $\rightarrow \quad$ wo...wó lài l-liáng....ahem sorry \\ I... I want $t$-two ... atem sorry \\ try again \\ 3 wo lài liáng ge bàozi ((wrong tone)) \\ I want two buns ((wrong tone))}

In Excerpt 7, Sue is reading the Chinese sentence. There is a short pause and 'ahem' before Sue's sorry (line 1), then she says, 'try again' (line 2). This indicates that Sue would like to produce another sound after she negatively evaluates her prior utterance and would like to remake it correctly, although she fails again in the correct pronunciation (in line 3, with incorrect tones for three Chinese words). The sorry used by Sue is her negation of what she just said and foretells a self-correction.

\section{Excerpt 8}

$1 \quad$ Ignacio: $\rightarrow \quad$ ni xi Zhōngguǒ ren hai xi Japanese
areyou Chinese or Japanese
ren?@@@sorry
people?@@@sorry

The context for Excerpt 8 is a learner learning expressions of nationality in Chinese, for which the format is the name of the state plus ren (people), i.e., Zhongguo (China) plus ren (people) to format the word meaning 
'Chinese'. The learner Ignacio intends to ask the tutor in Chinese whether he is Chinese or Japanese (lines 1 and 2). However, because Ignacio cannot use the word Riben (Japan) in Chinese, he code-switches from Chinese to English to say Japanese and then adds the Chinese word 'ren'. Ignacio is aware that the word (Japanese plus ren) he just uttered is an incorrect and odd expression. He first laughs at himself, then says sorry to deny the utterance. Note that after sorry, Ignacio does not make a correction to 'Japanese ren' because he does not know how to say Japan in Chinese. Sorry used here may serve a double function: to deny a prior utterance and to call for other-correction.

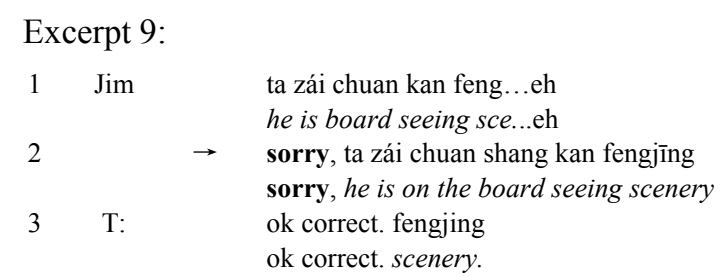

In Excerpt 9, Jim stops before completing the sentence (line 1) because he finds that his expression has a grammatical mistake in that the Chinese preposition 'shang' (on) for 'chuan' (board) is missing. After '...eh' to obtain time to think, he uses sorry to display his wish to cancel his prior utterance and reproduce another one with correct grammar (line 2). His correction receives the tutor's confirmation (line 3 ).

\subsection{Use of Sorry with Negative Operator No}

Some cases of sorry in the data, as exemplified by the following excerpt, are accompanied by no, the operator for negation. This use further demonstrates that sorry in this context has the same function as the negative operator no.

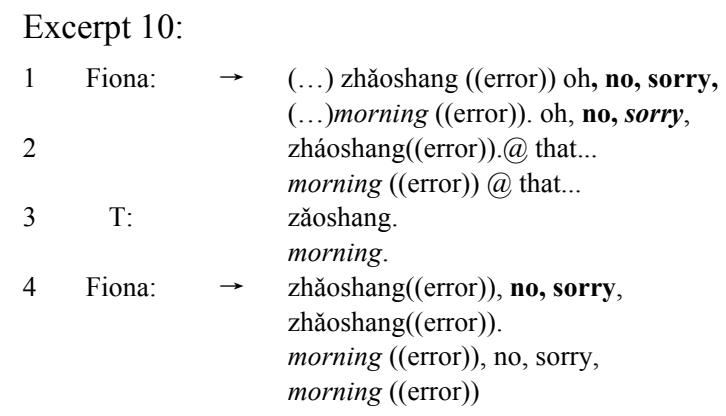

Fiona pronounces the initial consonant ' $\mathrm{z}$ ' like ' $\mathrm{zh}$ ' for the Chinese word 'zaoshang' (morning) in Excerpt 10 when she practices pronouncing some newly learned Chinese words. Fiona recognizes the problem after she says 'zhaoshang' (which should be zaoshang in line 2), and she says 'oh, no, sorry' and then re-pronounces the word again (in line 3), though it is still incorrect. After the tutor demonstrates the correct pronunciation (line 3), Fiona repeats her previous statement (line 4). Before sorry, Fiona also uses the negation operator no, which shows her strong wish to cancel what she just uttered because she was not satisfied by it and wants to make a correction. Similar to some other cases, after no, sorry, Fiona actually repeats her utterance without change. This phenomenon indicates that although a speaker-learner may be strongly dissatisfied with his/her prior utterance and wishes to recast it, there may be no significant improvement in the reproduction because of their unfamiliarity with the language.

Another example of the use of no and sorry together can be found in Excerpt 11 below.

\begin{tabular}{|c|c|c|}
\hline \multicolumn{3}{|c|}{ Excerpt 11} \\
\hline 1 & Garry: & $\begin{array}{l}\text { shi. wo shi...wo shi Méiguoren. } \\
\text { yes, I am ... I am American. }\end{array}$ \\
\hline 2 & $\mathrm{~T}$ : & $\begin{array}{l}\text { ni zai Meiguo zhu nali? } \\
\text { do you live in America where? }\end{array}$ \\
\hline 3 & Garry: $\rightarrow$ & $\begin{array}{l}\text { wo zhu nali...er no, sorry. } \\
\text { I live where...er no, sorry. }\end{array}$ \\
\hline 4 & & $\begin{array}{l}\text { wo zhu zai Kēntaji. } \\
\text { I live in Kentucky. }\end{array}$ \\
\hline 5 & & $\begin{array}{l}\text { ni de jia zai nali? } \\
\text { your hometown is where? }\end{array}$ \\
\hline
\end{tabular}

In Excerpt 11, the class is learning how to say 'hometown' in Chinese. After the tutor asks Garry where his home is in the United States (line 2), Garry partially repeats the tutor's question first (line 3 ), then pauses briefly with the interjection $e r$ when he realizes that the response he just made is wrong. After er, Garry says no and then sorry (line 3) to indicate that he would like to cancel his incorrect response, and he subsequently produces a correct one.

It is interesting that if no is a negative operator and sorry is also a marker of negation, as claimed by this study, does the combined usage of no and sorry function as a double negation, which can logically be an affirmation? The answer is definitely no. How does the combined usage of no and sorry function? The answer is a double emphasis. The speaker treats sorry as a supplementary word or equivalent to no to doubly emphasize the negation of her/his prior utterance (e.g., 'zhaoshang' in Fiona's case in Excerpt 10 and 'wo zhu nali' in Garry's case in Excerpt 11, both of which are presented incorrectly). Thus, the function of sorry used with no is to strengthen the self-negation.

\subsection{Self-negation Calling for Other Correction}

We have seen some of examples above that self-negation of problematic utterances results in self-correction. However, this may not be always the case. Using sorry as a marker for self-negation may function as a call for other-correction in classroom interaction.

\begin{tabular}{|c|c|c|c|}
\hline \multicolumn{4}{|c|}{ Excerpt 12} \\
\hline 1 & Bolin: & & $\begin{array}{l}\text { ok, um, zhăoshang ((error)) hăo. yi, oh.. } \\
\text { ok, um, morning ((error)) good. yi, oh... }\end{array}$ \\
\hline 2 & $\mathrm{~T}:$ & & ah ... \\
\hline 3 & Bolin: & $\rightarrow$ & you know. sorry \\
\hline 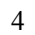 & $\mathrm{T}:$ & & zh:...z::ăo \\
\hline & Bolin: & & zhăo ((error)). \\
\hline
\end{tabular}


In this excerpt, Bolin practices the Chinese phrase 'zaoshang hao' (good morning), which she has difficulty pronouncing (line 1). After she utters the phrase, she says 'you know, sorry', which may be interpreted as 'as you know, my pronunciation is problematic; it is not correct'. Following her sorry, the tutor demonstrates the correct pronunciation, and then Bolin follows, though she still does not correct her error (line 5). It should be noted that sorry used by Bolin does not cancel her utterance of 'you know' (line 3) but cancels what she said previously ('zhaoshang hao' in line 1), which is indicated by 'you know'. Furthermore, sorry as used by Bolin is not for self-correction but rather to call for another's help (the tutor's correction).

\section{Excerpt 13 \\ 1 Jim: mái jian háo de yifu, duo hua yidián buying a good clothes, more \\ 2 qian ye jīde...g-de ((error)) money spending is wor(th) ... wor((error)) \\ $3 \rightarrow$ can't remember the (last one) sorry}

Sorry in Excerpt 13 has the same function as in Excerpt 12. Jim cannot correctly pronounce the last word of the sentence. After using sorry to negate his utterance of 'jide...g-de' (line 2), he stops attempting the pronunciation. Sorry here serves the same function as in Excerpt 12 by calling for another's help in correction.

\section{Discussion}

Based on an analysis of 40 cases of sorry as a marker for self-negation, some discourse and pragmatic features of sorry in learners' speaking, have identified. This analysis provides evidence to support or not support theoretical arguments in the study of pragmatic negation.

Although sorry can be used as a truth-functional operator for propositions, as demonstrated in Excerpts 2 and 3 , it is prominently used by speaker-learners as a device for objecting to a previous utterance in conversational implicature or other aspects of the use of language, as demonstrated by Excerpts 4-8. Therefore, sorry occurs more often as discourse-oriented negation.

The instances of sorry used in the context of language classroom, as analyzed, have two pragmatic meanings. First, sorry serves as a marker for self-negation that indicates that a speaker-learner is dissatisfied with what $\mathrm{s} / \mathrm{he}$ just uttered and provides an opportunity to correct or recast her/his utterance. Second, it indicates that the speaker-learner takes responsibility for mistakes in his/her utterance before obtaining help from the tutor, who should be responsible for correcting the learner's mistakes in the learning process. Thus, the use of sorry can help a speaker to hold the floor to produce another utterance before moving the interaction forward. This is why sorry, in most cases, is followed by a self-correction. In addition, this is why sorry is employed as a marker for self-negation, because it reflects its two lexical meanings - apology and no- simultaneously.

However, in some cases (Excerpts 5, 8, 12 and 13), after self-negating a prior utterance, a corrective continuation is not presented by the speaker of the difficulty, although this is possible, and the next turn is taken by others who make the corrections. In this situation, sorry functions as an initiation for correction by another which can also be considered pragmatic negation.

In all examples of sorry, followed by a corrective utterance, whether by the speaker of the problematic utterance or others sorry can be interpreted as a negation-correction pattern which is typical of pragmatic negation. Since the corrective continuation is initiated by sorry, which appears immediately after the trouble utterance, it should be considered an additional argument for its 'diagnostic value' (Horn [1], p.140; Foolen [13], p. 222).

As a negation-correction pattern, the negative evaluation embodied in sorry has a positive effect on the ongoing interaction as well as for language learning in the classroom context. In this context, the negative lexical meaning can have a positive pragmatic function because the negative term is denying an error.

As self-negation, two types of sorry used by speaker-learners have been identified: sorry used with the negation operator no and sorry used without no. The analyses show that for self-negation of a prior utterance, the two types of sorry have the same informative effect. In other words, there is no communicative difference in the two types. In speaker-learner's talk, either sorry or no can be used to cancel a prior utterance, and sorry and no can also be used together. However, when it accompanies no, sorry may be stronger as an expression of the rejection of a prior utterance, which may encourage hearers to wait for the speaker to make a self-correction. The type of sorry with no may have a strengthened effect on negation in addition to either sorry or no used alone, but the double negation does not logically have the opposite effect of an affirmation. In this sense, although sorry is used as a marker of self-negation in the context of language learning, it is not entirely equal to the function of the negative operator no.

The use of sorry has a dual function. It can make negation mild or uncertain (it is softer than 'no', although following it with no is a stronger negation). Because an utterance was made in an L2, the speaker expects others to allow him/her to recast or reformulate the utterance and to make an excuse to others (the tutor and other learners in the class) for his/her mistake or to hold the floor for self-correction.

As a strategy for pragmatic negation, the use of sorry can indicate that the speaker, as a learner, is willing to cancel his/her utterance and express his/her attitude toward the next utterance or turn (e.g., to continue to hold the floor, give up the floor, or request another's correction). 
There are at least two reasons for using sorry instead of directly using the negative operator no. First, saying sorry is a convenient way to deny the speaker's previous utterance and to describe the speaker-learner's mistake in the use of another language parsimoniously. As both a language user and a language learner, the speaker cannot describe exactly which part of his utterance is wrong due to the speaker's limited competence in using the language. In fact, if it is not necessary or there is no time in the classroom to allow the learner to indicate his/her mistakes, the use of sorry can deny the previous utterance as a whole, and the speaker-learner can do whatever s/he would like to do in the next utterance. Second, given its sequential status, cancelling a prior utterance and holding the floor for reuttering, from an interpersonal perspective, may tend to be face-threatening. Sorry as a term with the lexical meaning of apology seems to be the most suitable word for language learners to express regret in a polite way and soften the tone for self-negation during their interaction with others in the learning process. This may be why sorry plays a role as a marker of self-negation in this context. Therefore, sorry is the most proper word that can be used in this situation, because its two lexical meanings - apology and $n o-$ can be realized simultaneously.

\section{Conclusions}

This study investigates the role of sorry as a marker for self-negation used by speaker-learners in ongoing talk in the classroom and identifies its functions for negative evaluation and negation of a prior utterance by a learner self.

Detailed analyses show that rather than using sorry as a negation for a truth-functional operator for propositions, it is prominently used by speaker-learners as a device for objecting to a previous utterance in conversational implicature or other aspects of the use of language, which is related to pragmatic negation. The findings from the study also show that sorry plays a dual role by negating the prior utterance and predicting the next utterance, which may be by the speaker or by the hearer, for correction. In this context, sorry is used beyond its single lexical meaning of either apology or no but rather combines the two, which can be perceived and maturely understood by speakers and hearers. This is the possible reason for sorry being employed as a marker for pragmatic negation.

As a marker of self-negation, sorry can be used with or without the association of the negative operator no, and there is no communicative difference between the two. However, when it accompanies the negative operator no, the self-negation of sorry can be strengthened, and it is more likely that self-correction, not other-correction, will follow.

As an alternative form of negation, sorry carries a positive function in the context of language learning and embodies a mechanism for speaker-learners' self-monitoring and self-correction in the process of classroom interaction.

The relationship of the semantic and pragmatic meanings of a word (sorry in this study) in natural use is an interesting issue that requires further exploration.

\section{Transcription Convention}

\begin{tabular}{|c|l|}
\hline pinyín & $\begin{array}{l}\text { tone mark indicating the Chinese syllable ‘yín' uttered } \\
\text { with the incorrect tone, whereas 'pin' is correct }\end{array}$ \\
\hline bold & instance of sorry under scrutiny \\
\hline Chinese & English translation from Chinese by the author \\
\hline$\ldots$ & pauses or intervals \\
\hline @@ & laugher \\
\hline$($ words $)$ & possible words \\
\hline$(($ note) $)$ & Annotation / comment made by researcher \\
\hline$(\ldots)$ & irrelevant words omitted by researcher \\
\hline$\rightarrow$ & turn with sorry under analysis \\
\hline$::$ & prolonged voice \\
\hline
\end{tabular}

\section{Acknowledgements}

The work described in this paper was fully supported by a grant from the Research Grants Council of the Hong Kong Special Administrative Region, China (UGC/FDS16/H15/14).

\section{REFERENCES}

[1] L.R. Horn. Metalinguistic negation and pragmatic ambiguity, Language, Vol.61, No.1, 121-174, 1985.

[2] O. Ducrot. Dire et ne pas Dire. Paris: Herraann. 1972. Cited in L.R. Horn. Metalinguistic negation and pragmatic ambiguity. Language, Vol.61, No.1, 121-174, 1985.

[3] Ducrot, O. La Prevue et le Dire. Paris: Maison Mame. 1973. Cited in Horn, L.R. Metalinguistic negation and pragmatic ambiguity. Language, Vol.61, No.1, 121-174, 1985.

[4] G. Kruszewski, D. Paperno, R. Bernardi, M. Baroni. There is no logical negation here, but there are alternatives: Modeling conversational negation with distributional semantics, Computational Linguistics, Vol. 42, No.4, 637-660, 2016.

[5] C. Jiang. Nature and categorization of metalinguistic negation, Theory and Practice in Language Studies, Vol.5, No.3, 598-604, 2015.

[6] P. Rozin, E.B. Royzman. Biases in use of positive and negative words across twenty natural languages. Cognition and Emotion, Vol. 24, No. 3, 536-548, 2010.

[7] D. Garcia, A. Garas, F. Schweitzer. Positive words carry less information than negative words. EPJ Data Science, Vol.1, 
No.3, 1-12, 2012.

[8] M. Taboada, R. Trnavac, C. Goddard. On Being Negative, Corpus Pragmatics, Vol.1, 57-76, 2017.

[9] D. Biber, F. Barbieri. Lexical bundles in university spoken and written registers, English for Specific Purposes, Vol.26, 263-286, 2007.

[10] L. T. Sousa. Three types of negation in Brazilian Portuguese, Lingua Vol.159, 27-46, 2015.

[11] I. Orenes, L. Moxey, C. Scheepers, C. Santamaría. Negation in context: Evidence from the visual world Paradigm. The Quarterly Journal of Experimental Psychology, Vol. 69, No.6, 1082-1092, 2016.

[12] L.R.Horn, H. Wansing. Negation. In E.N. Zalta (Ed.), The Stanford Encyclopedia of Philosophy. 2015. Online available from https://plato.stanford.edu/entries/negation/

[13] A. Foolen. Metalinguistic negtion and pragmatic ambiguity: Some comments on a proposal by Laurence Horn. Pragmatics, Vol.1, No.2, 217-237, 1991.

[14] P. Drew. 'Open' class repair initiators in response to sequential sources of troubles in conversation. Journal of Pragmatics, Vol. 28, No.1, 69-101, 1997.

[15] J. Robinson. The sequential organization of "explicit" apologies in naturally occurring English. Research on Language and Social Interaction, Vol.37, No.3, 291-330, 2004 .
[16] J. Robinson. Managing Trouble Responsibility and Relationships during Conversational Repair. Communication Monographs, Vol. 73, No.2, 137-161, 2006.

[17] C. S. Rhys. Choosing not to repair: Sorry as a warrant for interactional progress. Research on Language and Social Interaction, Vol. 46, No.1, 84-103, 2013.

[18] L. Alba-Juez, E. Martínez-Caro. The evaluative function as part of the hidden pragmatic meaning of certain expressions in English and Spanish. Rocky Mountain Review, Vol. 65, No.2, 188-207, 2011.

[19] C. Potts. On the negativity of negation. In Procedings of SALT 20: Semantics and Linguistic Theory (pp. 636-659), Vancouver. 2011. Cited in M. Taboada, R. Trnavac, C. Goddard. On Being Negative, Corpus Pragmatics, Vol.1, 57-76, 2017.

[20] J. Channel. Corpus-based analysis of evaluative lexis. In Hunston, S. and Thompson, G. (Eds.) Evaluation in Text. Authorial Stance and the Construction of Discourse, Oxford, Oxford University Press, 38-55. 1999.

[21] I. Hutchby, R. Wooffitt. Conversation analysis ( $2^{\text {nd }}$ Edition). Polity Press, Cambridge, Malden, MA, 2008.

[22] G. Jefferson. Glossary of transcript symbols with an introduction. In G.H. Lerner (Ed.) Conversation Analysis: Studies from the First Generation (pp.13-31), John Benjamins, Amsterdam, 2004. 